\title{
Tumor Necrosis Factor-a-induced Inhibition of Phosphatidylcholine Synthesis by Human Type II Pneumocytes Is Partially Mediated by Prostaglandins
}

\author{
Javier Arias-Díaz, Elena Vara, * Cruz García, * and José L. Balibrea \\ * Department of Biochemistry, Facultad de Medicina, and Department of Surgery, Hospital Universitario San Carlos, \\ Universidad Complutense, 28040-Madrid, Spain
}

\begin{abstract}
TNF $\alpha$ seems to play an important role in the pathogenesis of adult respiratory distress syndrome. We studied the effect of TNF $\alpha$ on phospholipid synthesis by isolated type II pneumocytes and attempted to characterize the role of arachidonate metabolites and the influence of pentoxifylline on such an effect. Lung tissue obtained from both multiple organ donors $(n=14)$ and lung cancer patients $(n=11)$ was used for cell isolation. Surfactant synthesis was measured by the incorporation of $\mathrm{D}-\left[\mathrm{U}-{ }^{14} \mathrm{C}\right]$ glucose into phosphatidylcholine (PC). The basal PC synthesis was higher in the donor group than in the malignant group $(3.44 \pm 0.19$ vs $2.15 \pm 0.15 \mathrm{pmol} /$ $\mu \mathrm{g}$ protein $\times 120 \mathrm{~min}, P<0.01)$, and, in the presence of $100 \mathrm{ng} / \mathrm{ml}$ of $\mathrm{TNF} \alpha$, the incorporation of labeled glucose into $\mathrm{PC}$ was reduced significantly in both donor $(1.13 \pm 0.11$ vs $3.44 \pm 0.19 \mathrm{pmol} / \mu \mathrm{g}$ protein $\times 120 \mathrm{~min}, P<0.01)$ and cancer $(0.99 \pm 0.11$ vs $2.15 \pm 0.15 \mathrm{pmol} / \mu \mathrm{g}$ protein $\times 120 \mathrm{~min}$, $P<0.01)$ groups. Indomethacin was able to completely block the cytokine-induced decrease in PC synthesis by pneumocytes from the malignant group and to attenuate the inhibitory effect of TNF $\alpha$ in those from donors, nordihydroguaiaretic acid having a similar effect. The TNF $\alpha$ effect can be blocked by pentoxifylline $(100 \mu \mathrm{g} / \mathrm{ml})$, a substance which can even succeed in reverting the basal secretory inhibition of cancer patients' pneumocytes to levels similar to those of the donor group. TNF $\alpha$ may contribute to the pathophysiology of adult respiratory distress syndrome by inhibiting the synthesis of surfactant. TNF $\alpha$ might be produced in lung tumors, resulting in chronic paracrine or systemic exposure of pneumocytes to low concentrations of the cytokine. The TNF $\alpha$ effect was not prevented completely by the blockage of the arachidonic acid metabolism, hence other mediators should also be implicated. (J. Clin. Invest. 1994. 94:244-250.) Key words: adult respiratory distress syndrome - lung cancer - pentoxifylline - indomethacin • nordihydroguaiaretic acid
\end{abstract}

\section{Introduction}

Macrophage-derived TNF $\alpha$ is a cytokine that is increasingly recognized as a central mediator in a wide spectrum of physio-

\footnotetext{
Address correspondence to Javier Arias-Díaz, M.D., Aptdo. Correos 60050, Ciudad Universitaria, 28040-Madrid, Spain.

Received for publication 23 August 1993 and in revised form 22 March 1994.
}

J. Clin. Invest.

(c) The American Society for Clinical Investigation, Inc.

0021-9738/94/07/0244/07 \$2.00

Volume 94, July 1994, 244-250 logic and immune functions. This molecule manifests a diverse range of biological effects, including tumoricidal activity and the wasting associated with chronic disease (1), and is assumed to serve as a proximal mediator in the evolution of septic shock (2). Giving TNF $\alpha$ to animals causes a syndrome similar to septic shock and induces acute lung injury with respiratory insufficiency and death (2). The mechanisms by which TNF $\alpha$ causes its effects have not been totally explained, but it is known that it can increase lung capillary permeability, has chemotactic properties for inflammatory cells, and is capable of activating neutrophils and endothelial cells (2).

Alterations in type II pneumocyte function, including surfactant biosynthesis, may have a significant role in the pathogenesis of sepsis-induced lung injury $(3,4)$. In addition to its endothelium-activating properties, TNF $\alpha$ can contribute to the physiopathology of adult respiratory distress syndrome (ARDS $)^{1}$ also by modifying the surfactant composition. In fact, TNF $\alpha$ has been found to be located principally within type II pneumocytes in both early and late stages of human ARDS (5).

The signal transduction mechanisms by which TNF $\alpha$ exerts its varied biological effects have not been fully elucidated. A number of findings suggest that the stimulation of prostaglandin synthesis may contribute to some of its biological effects. TNF $\alpha$ induces $\mathrm{PGI}_{2}$ production in endothelial cells and $\mathrm{PGE}_{2}$ production in human synovial cells and dermal fibroblasts (6). Furthermore, the release of arachidonic acid from phospholipids appears to be a critical element in the signaling pathway used by TNF $\alpha$ (7). Cyclooxygenase inhibitors have been shown to reduce the toxicity associated with TNF $\alpha$ administration (8), and there are also interesting reports of enhanced survival and improved physiology afforded by cyclooxygenase inhibitors in models of sepsis $(9)$ and ARDS $(8,9)$. The role of lipoxygenase products in mediating cytokine effects is less clear (10); nevertheless, maximal protection against TNF $\alpha$-mediated in vitro toxicity seems to be afforded when both cyclo- and lipoxygenase inhibitors are used together. Despite these data, the precise role of the arachidonic acid metabolites in the mediation of the TNF $\alpha$-induced lung injury remains unknown.

We designed this study to determine the effect of TNF $\alpha$ on phospholipid synthesis by isolated type II alveolar cells and to characterize the role of arachidonate metabolites on this effect. This was done by culturing type II human pneumocytes with TNF $\alpha$ in the presence and absence of indomethacin (cyclooxygenase inhibitor), nordihydroguaiaretic acid (NDGA) (lipoxygenase inhibitor), and/or prostaglandins.

1. Abbreviations used in this paper: ARDS, adult respiratory distress syndrome; DPPC, disaturated phosphatidylcholine; LPC, lysophosphatidylcholine; NDGA, nordihydroguaiaretic acid; PA, phosphatidic acid; PC, phosphatidylcholine; PE, phosphatidylethanolamine; PGL, phosphatidylglycerol; PI, phosphatidylinositol; PL, phospholipase; PPI, polyphosphoinositides; PTXF, pentoxifylline; SF, sphingomyelin. 
On the other hand, recent studies have shown that pentoxifylline (PTXF), an inhibitor of phosphodiesterase, reduces lung damage in septic animals and is capable of improving the hemodynamic manifestations and survival rate in experimental models of septic shock (11). In this study, we also analyzed the influence of PTXF on the TNF $\alpha$ effect.

To obtain the lung tissue used for isolating pneumocytes, we used previously healthy multiple organ donors and lung cancer patients and studied the possible differences between the two groups.

\section{Methods}

Patients and lung tissue procurement. Human lung tissue was obtained from portions of the right lower lobe from cadaveric multiple organ donors and from the nontumoral portion of the surgically excised right lower lobe from lung cancer patients.

The donor group was made up of 14 male patients diagnosed with brain death secondary to cranial trauma, with $<72 \mathrm{~h}$ of mechanical ventilation and with no radiological signs of lung infiltration. After harvesting the organs that were going to be used for transplantation, a right lower lobectomy was performed, and the pulmonary lobe was placed in cold saline solution.

The cancer group was made up of 11 male patients that underwent right pneumonectomy for squamous cell lung cancer that did not significantly affect the lower lobe. Lungs were placed immediately in cold saline, and the portion of the basal lobe farthest from the tumor was excised, washed, and then stored in cold saline solution.

The cadaveric as well as the cancer patient groups were operated on in our hospital institution. All donors and cancer patients had antecedent of recent tobacco smoking. The mean age was significantly different between groups $(40.9 \pm 5.1$ in the donors vs $59.4 \pm 3.7$ in the cancer group, $P=0.02$ by the Mann-Whitney test).

Chemicals. PTXF was purchased from Hoechst-Roussel Pharmaceuticals Inc. (Somerville, NJ). D- $\left[\mathrm{U}-{ }^{14} \mathrm{C}\right]$ glucose was from the Radiochemical Centre (Amersham, Bucks, UK). Elastase, 2',7'dichlorofluorescein, PGE $_{1}$, $\mathrm{PGE}_{2}$, indomethacin, NDGA, and standard lipids were from Sigma Chemical Co. (St. Louis, MO). Collagenase, human recombinant TNF $\alpha\left(2 \times 10^{7}\right.$ $\mathrm{U} / \mathrm{mg}$ ), and DNase were from Boehringer Mannheim GmbH (Mannheim, Germany). Percoll was from Pharmacia Fine Chemicals (Uppsala, Sweden). The RPMI 1640 medium and fetal bovine serum were from ICN Flow (High Wicombe, UK). All other chemicals were of analytical grade from E. Merck (Darmstadt, Germany).

Type II pneumocyte isolation procedure. All solutions were made with double-glass-distilled water. Solution I contained $140 \mathrm{mmol} /$ liter $\mathrm{NaCl}, 5 \mathrm{mmol} /$ liter $\mathrm{KCl}, 2.5 \mathrm{mmol} /$ liter $\mathrm{Na}_{2} \mathrm{HPO}_{4}, 10 \mathrm{mmol} / \mathrm{liter}$ Hepes, $6 \mathrm{mmol} /$ liter glucose, $0.2 \mathrm{mmol} /$ liter EGTA, and $10 \mu \mathrm{g} / \mathrm{ml}$ DNase. Solution II contained solution I with $2 \mathrm{mmol} /$ liter $\mathrm{CaCl}_{2}, 1.3$ $\mathrm{mmol} /$ liter $\mathrm{MgSO}_{4}, 27$ "orcein-elastin" units $/ \mathrm{ml}$ elastase, $10 \mu \mathrm{g} / \mathrm{ml}$ DNase, $0.5 \mathrm{mg} / \mathrm{ml}$ trypsin, and $0.5 \mathrm{mg} / \mathrm{ml}(2.7 \mathrm{IU} / \mathrm{mg})$ collagenase.

The time period between lobectomy and the beginning of isolation was never $>3 \mathrm{~h}$. The lung tissue was rinsed with solution I and minced into small pieces (1-3 mm), which were then washed extensively with the same solution to remove blood cells as much as possible. Subsequently, the portions were digested by two consecutive exposures, of 30 min each, to solution II in a $37^{\circ} \mathrm{C}$ shaking water bath. The tissue digestion was terminated by the addition of fetal calf serum at $4^{\circ} \mathrm{C}$, and the resulting cellular suspension was filtered through two nylon meshes (200 and $20 \mu \mathrm{m}$, respectively) and centrifuged at $250 \mathrm{~g}$ for $10 \mathrm{~min}$. After removing the supernatant, the pellets were resuspended in RPMI 1640 medium, added to $75-\mathrm{cm}^{2}$ flasks, precoated with fetal calf serum, and cultured in a $5 \% \mathrm{CO}_{2} / 95 \% \mathrm{O}_{2}$ air incubator at $37^{\circ} \mathrm{C}$ for $90 \mathrm{~min}$, during which most of the alveolar macrophages adhered to the plastic. After $90 \mathrm{~min}$, the nonadherent cells were removed, centrifuged $(250 \mathrm{~g}$ for $10 \mathrm{~min}$ ), and resuspended in solution I. For further purification, the suspension was applied to a Percoll gradient established by centrifuging
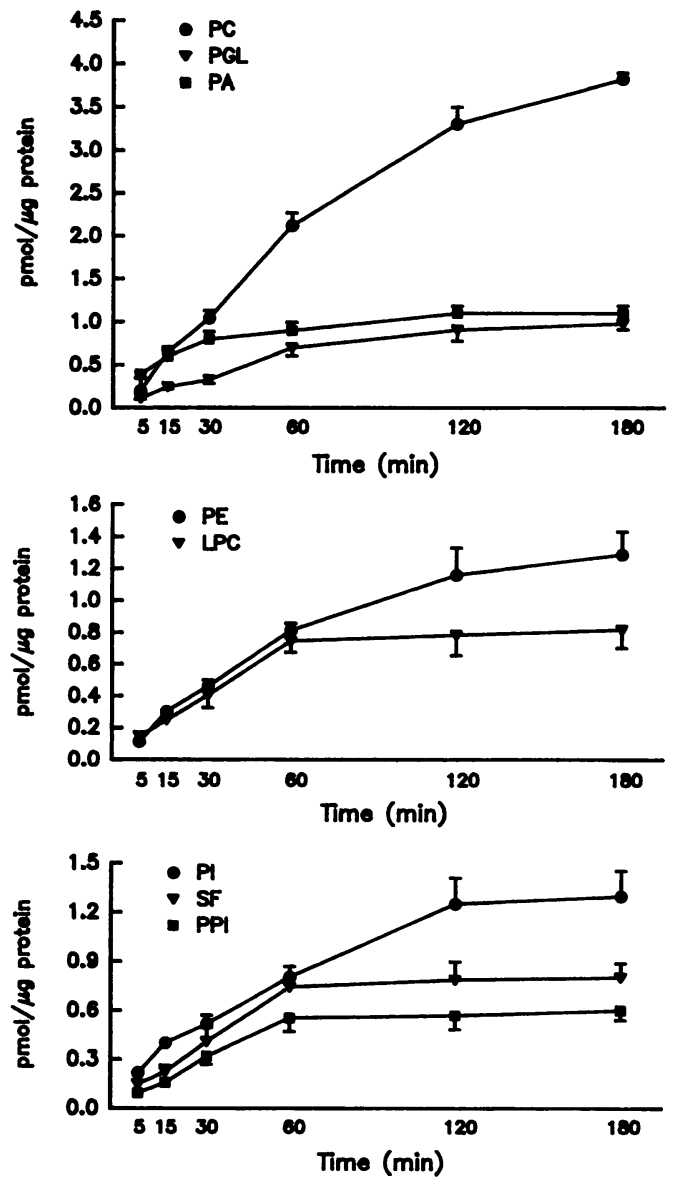

Figure 1. D- $\left[\mathrm{U}-{ }^{14} \mathrm{C}\right]$ glucose incorporation into different phospholipid fractions by type II pneumocytes isolated from multiple organ donors $(n=7)$ after being incubated for $5,15,30,60,120$, or $180 \mathrm{~min}$ in the absence of additives (PC, PGL, PA, PE, LPC, phosphatidylserine and PI, SF, and PPI).

the combination of Percoll with phosphate-buffered saline $(25 \mathrm{mmol} /$ liter $\mathrm{NaH}_{2} \mathrm{PO}_{4}, 300 \mathrm{mmol} /$ liter $\mathrm{NaCl}, \mathrm{pH} \mathrm{7.4)}$ ), in a 6:7 (vol/vol) ratio for $10 \mathrm{~min}$ at $20,000 \mathrm{~g}(12)$. Cells were counted in a standard hemacytometer. The mean yields obtained from the donor and cancer groups were $5.5 \pm 0.9$ and $5.1 \pm 0.8 \times 10^{6}$ cells $/ g$ of tissue, respectively. The percentage of cells that excluded trypan blue was $92.1 \pm 6.9 \%$ in the donor group and $89.4 \pm 6.3 \%$ in the cancer group. To determine the purity of the type II pneumocyte preparation $(85.8 \pm 6.2$ and $82.4 \pm 6.0 \%$ in the donor and cancer groups, respectively), both the modified Papanicolaou stain and the tannic acid and polychrome stain (13) were used. There were no statistical differences between the two groups with regard to the yield of type II cells or the purity or viability of the preparation.

Phospholipid synthesis. Surfactant synthesis was measured by using the incorporation of $10 \mathrm{mmol} /$ liter $\mathrm{D}-\left[\mathrm{U}-{ }^{14} \mathrm{C}\right]$ glucose $(12.5 \mathrm{Ci} / \mathrm{mol}$, uniformly labeled) into its most important phospholipid component, phosphatidylcholine (PC), as an index. To accomplish this, type II pneumocytes $\left(10^{6}\right.$ cells $/ \mathrm{ml}$ ) were incubated (collagen A-precoated microwells) in Krebs-Ringer bicarbonate medium supplemented with $0.5 \%$ human albumin, buffered with Hepes, and equilibrated, at a $\mathrm{pH}$ of 7.4, with a 9:1 mixture of $\mathrm{O}_{2} / \mathrm{CO}_{2}$. In the time-kinetic study (Fig. 1), the cells were preincubated for $30 \mathrm{~min}$ at $37^{\circ} \mathrm{C}$ in $50 \mu \mathrm{l}$ of the medium described above, and the incubation continued for different time lengths after addition of another $50 \mu$ l of the same medium supplemented with the isotope. In the other experiments, the cells were incubated with D[ $\mathrm{U}-{ }^{14} \mathrm{C}$ ] glucose for $120 \mathrm{~min}$ in the presence or absence of the different additives: TNF $\alpha(0,50,100$, and $500 \mathrm{ng} / \mathrm{ml}), \operatorname{PTXF}(100 \mu \mathrm{g} / \mathrm{ml}), \mathrm{PGE}_{1}$ 
or $\mathrm{PGE}_{2}\left(10^{-7} \mathrm{~mol} / \mathrm{liter}\right)$, indomethacin ( $\left.30 \mu \mathrm{mol} / \mathrm{liter}\right)$, or NDGA (30 $\mu \mathrm{mol} / \mathrm{liter})$. At the end of the incubation, the cells were rapidly frozen in acetone chilled with dry ice. After adding acid methanol $(0.7 \mathrm{ml})$ to the tubes, the contents were sonicated in an MSE Ultrasonic Disintegrator (Branson, Danbury, CT). Then, the lipids were extracted with 1.3 $\mathrm{ml}$ of chloroform and $0.4 \mathrm{ml}$ of salt solution for $1 \mathrm{~h}$ at room temperature. The organic phase was then washed three times with $1.0 \mathrm{ml}$ of the aqueous phase of a system composed of chloroform/methanol/salt solution/concentrated $\mathrm{HCl}$ (266:133:100:1, vol/vol), after the addition of $30 \mu \mathrm{l}$ of carrier lipids in chloroform/methanol/concentrated $\mathrm{HCl}$ (200:100:1, vol/vol). The organic phase was dried under $\mathrm{N}_{2}$ and redissolved in $40 \mu \mathrm{l}$ of chloroform/methanol (2:1, vol/vol). Samples (30 $\mu \mathrm{l})$ of the redissolved organic phase were then applied to precoated plates of Silica Gel $60(20 \times 20 \mathrm{~cm}$; E. Merck $)$ previously activated for $1 \mathrm{~h}$ at $110^{\circ} \mathrm{C}$. Lipid separation was performed by unidimensional chromatography with two solvent systems, as described previously in detail (14). After the plates had been sprayed with 2'7'-dichlorofluorescein, the following spots were detected under ultraviolet light and identified with adequate markers: polyphosphoinositides (PPI) (origin), lysophosphatidylcholine (LPC), sphingomyelin (SF), PC, phosphatidylserine and phosphatidylinositol (PI), phosphatidylethanolamine (PE), phosphatidic acid (PA), and phosphatidylglycerol (PGL). Each spot was scraped off into a scintillation vial, and its radioactivity was measured. To exclude any "carry-through" of unincorporated label, experiments in which label was added just before freezing cells were used as control.

In experiments done separately, the effect of TNF $\alpha$ and PTXF on disaturated phosphatidylcholine (DPPC) synthesis was examined. To do this, we reacted the total PC fraction with osmium tetroxide in carbon tetrachloride and then separated the saturated species of PC from the unsaturated ones by thin-layer chromatography on silica-gel plates impregnated with boric acid, using chloroform:methanol:ammonium hydrochloride:water (75:25:1:2). Different amounts of a standard DPPC solution were spotted directly onto the plates. To estimate the recovery of disaturated species from the initial sample, we repeated the procedure with samples of radioactive saturated PC. The recovery was $78.2 \pm 5.1 \%$ $(n=5)$.

A frozen aliquot of the cellular suspension was stored for the determination of proteins, which was done by the Coomassie brilliant blue spectrophotometric method.

Chromium-51 release assays. To exclude the possibility of a nonspecific TNF $\alpha$ effect due to cytotoxicity, we measured cell lysis by a standard chromium-51 release assay. Cells were labeled by incubation at $37^{\circ} \mathrm{C}$ in $150 \mu \mathrm{l} \mathrm{RPMI} 1640 \mathrm{medium} /$ well with $2 \mu \mathrm{Ci}{ }^{51} \mathrm{Cr}$-labeled sodium chromate for $24 \mathrm{~h}$ and then washed four times. The TNF $\alpha$ was diluted in RPMI 1640 medium and added to the cell culture; the plates were incubated at $37^{\circ} \mathrm{C}$ for $24 \mathrm{~h}$, after which an aliquot $(100 \mu \mathrm{l})$ of the medium was collected and counted in a gamma counter. Specific cell lysis was calculated as $100 \times$ (test medium cpm - spontaneous cpm total $\mathrm{cpm}$ - spontaneous $\mathrm{cpm}$ ). Spontaneous release of chromium-51 measured in wells incubated in RPMI 1640 medium alone was $<20 \%$ of total chromium-51 release, which was measured by dissolving the cells in 4\% Triton X-100 for $6 \mathrm{~h}$. In the presence of $100 \mathrm{ng} / \mathrm{ml} \mathrm{TNF} \alpha$, the cell lysis (percentage of chromium-51 release above spontaneous release) was insignificant.

Statistical analysis. The results are expressed in picomoles (of incorporated labeled precursor) per microgram of protein (mean \pm SEM). Multiple comparison of means was done by Friedman's analysis of variance of ranks, followed by a two-tailed Wilcoxon's rank sum test for paired data to identify the source of the differences found; $P$ values $<0.05$ were considered to be indicative of statistically significant differences. The Mann-Whitney test was used for comparisons between the donor and cancer groups. To discover any intragroup correlation between a patient's age and surfactant synthesis, we used the Spearman's ranks correlation test in both groups.

\section{Results}

Fig. 1 shows the time-dependent incorporation of $\mathrm{D}-\left[\mathrm{U}-{ }^{14} \mathrm{C}\right]-$ glucose into the different phospholipid fractions by type II pneu-

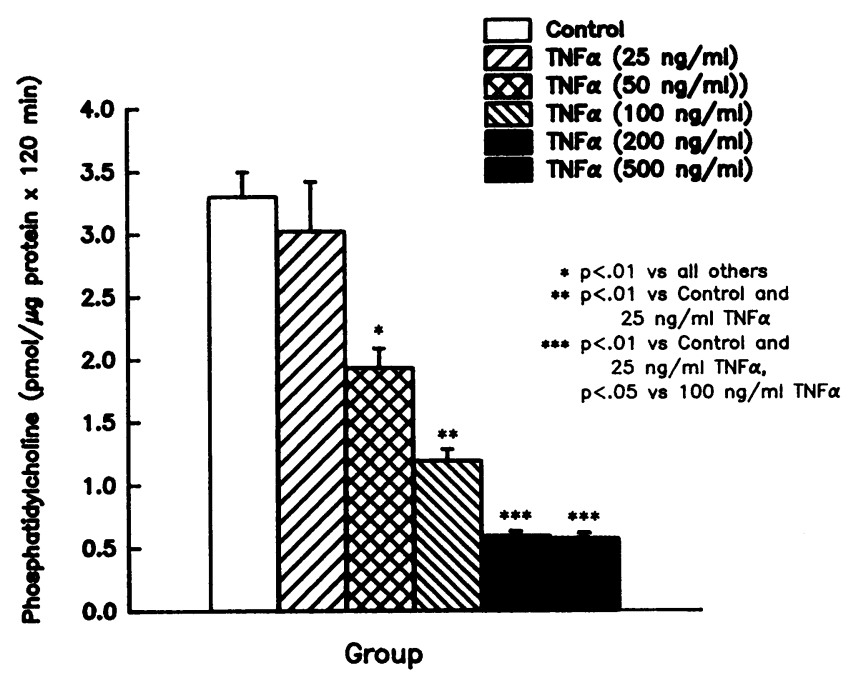

Figure 2. Relationship between concentration of TNF $\alpha$ into the medium and $\mathrm{D}-\left[\mathrm{U}-{ }^{14} \mathrm{C}\right]$ glucose incorporation into $\mathrm{PC}$ by type II pneumocytes isolated from multiple organ donors $(n=7)$ and incubated for $120 \mathrm{~min}$.

mocytes isolated from multiple organ donors. The incorporation of labeled glucose increased progressively with time in all lipid fractions. Isotopic equilibrium was apparently reached between 30 and 60 min, except for PC fraction which showed a tendency to reach isotopic equilibrium between 120 and $180 \mathrm{~min}$.

After $120 \mathrm{~min}$ of incubation, TNF $\alpha$ decreased, in a dosedependent fashion, the synthesis of PC by type II pneumocytes isolated from donors (Fig. 2). Maximal effect was apparently reached at $200 \mathrm{ng} / \mathrm{ml}$.

When the effect of cancer on phospholipid metabolism was investigated, we found that the basal PC synthesis was higher in the donor group than in the malignant group. Cancer also decreased LPC and PGL labeling, while the incorporation of labeled glucose into the other phospholipid fractions was similar in both groups (Fig. 3).

In the presence of $100 \mathrm{ng} / \mathrm{ml}$ of TNF $\alpha$, the incorporation

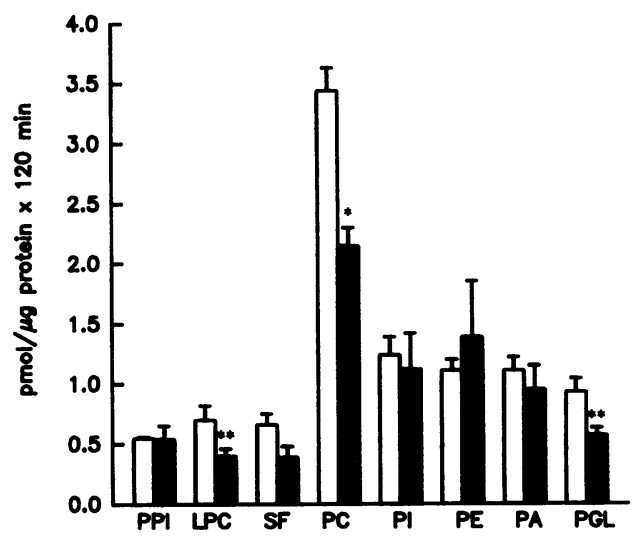

Figure 3. D- $\left[\mathrm{U}-{ }^{14} \mathrm{C}\right]$ glucose incorporation into different phospholipid fractions by type II pneumocytes isolated from either multiple organ donors (white bars) $(n=14)$ or lung cancer patients (hatched bars) $(n=11)$ after being incubated for $120 \mathrm{~min}$ in the absence of additives (PPI, LPC, SF, PC, phosphatidylserine and PI, PE, PA, and PGL). ${ }^{*} P$ $<0.01$ vs donor; ${ }^{* *} P<0.05$ vs donor. 
of $\mathrm{D}-\left[\mathrm{U}-{ }^{14} \mathrm{C}\right]$ glucose into $\mathrm{PC}$ was reduced significantly in both donor and cancer groups (Fig. 4); in contrast, no changes were observed in the labeling of the other phospholipid fractions investigated. PTXF completely blocked the effect of TNF $\alpha$ in pneumocytes from the donor group and increased PC synthesis in those from the malignant group (both with and without TNF $\alpha$ ) to a value similar to that in pneumocytes from the donor group in the absence of additives (Fig. 4).

To investigate whether the TNF $\alpha$-induced decrease in PC synthesis was mediated by prostaglandins, we first studied the effect of $\mathrm{PGE}_{1}$ and $\mathrm{PGE}_{2}$. As occurred with TNF $\alpha$, both $\mathrm{PGE}_{1}$ and $\mathrm{PGE}_{2}$ reduced the incorporation of $\mathrm{D}-\left[\mathrm{U}-{ }^{14} \mathrm{C}\right]$ glucose into $\mathrm{PC}$ in both donor and cancer groups (Fig. $5 A$ ), and this effect was not additive with that of TNF $\alpha$ (Fig. $5 B$ ). However, in contrast with what happened with the TNF $\alpha$ effect, PTXF just partially reversed the prostaglandin effect (Fig. 4).

We next sought to investigate the effect of cyclooxygenase and lipoxygenase blockade on PC synthesis. Fig. $6 B$ shows that indomethacin was able to completely block the cytokineinduced decrease in labeled glucose incorporation into PC by type II pneumocytes from the malignant group and to attenuate the inhibitory effect of TNF $\alpha$ in those from the donor group. Administration of NDGA had a similar effect (Fig. $6 \mathrm{~B}$ ). Neither indomethacin nor NDGA modified PC synthesis in the absence of TNF $\alpha$ (Fig. $6 \mathrm{~A}$ ).

After $2 \mathrm{~h}$ of incubation, the radioactivity in DPPC comprised about $58 \%$ of the label incorporated into total PC in both donor and cancer groups. In the presence of TNF $\alpha$, PTXF, or both, the results were similar to those observed for total PC (data not shown).

No correlation was found between patient age and PC synthesis when studied separately in the donor $(r=-0.03$, $P=0.92)$ and cancer $(r=-0.30, P=0.36)$ group.

\section{Discussion}

There is a growing body of evidence to suggest that TNF $\alpha$ and other cytokines mediate endotoxemia and ARDS (2). TNF $\alpha$ is secreted by alveolar macrophages after endotoxin exposure (2), and, among other cellular types, type II pneumocytes may represent a target for this cytokine (5). Alteration in the synthesis or composition of surfactant may have an important role in the pathogenesis of ARDS $(3,4)$, and a close correlation between alterations in the lipid composition of bronchoalveolar lavage fluid and a predisposition to ARDS has been demonstrated in polytraumatized patients (15).

This work shows that TNF $\alpha$ has an inhibitory effect on the de novo synthesis of $\mathrm{PC}$, the main component of pulmonary surfactant. This finding agrees with previous in vivo results (2, 16) and suggests that TNF $\alpha$ participates in the physiopathology of ARDS by this mechanism. Dipalmitoylphosphatidylcholine is specific to surfactant, while PC itself is not; to test the assumption that the total PC was an adequate marker of its disaturated fraction in our system, we studied the effect of TNF $\alpha$ and PTXF on DPPC synthesis in separate experiments, observing a complete parallelism in the synthesis of both fractions.

The lower basal synthesis rate of PC found in the cancer group could, hypothetically, be also mediated in vivo by TNF $\alpha$. It is known that lung cancer cells can secrete an abundance of growth factors and cytokines, including TNF $\alpha$, without prior exogenous stimulation (17). Furthermore, the alveolar macrophages of lung cancer patients seem to be primed to produce

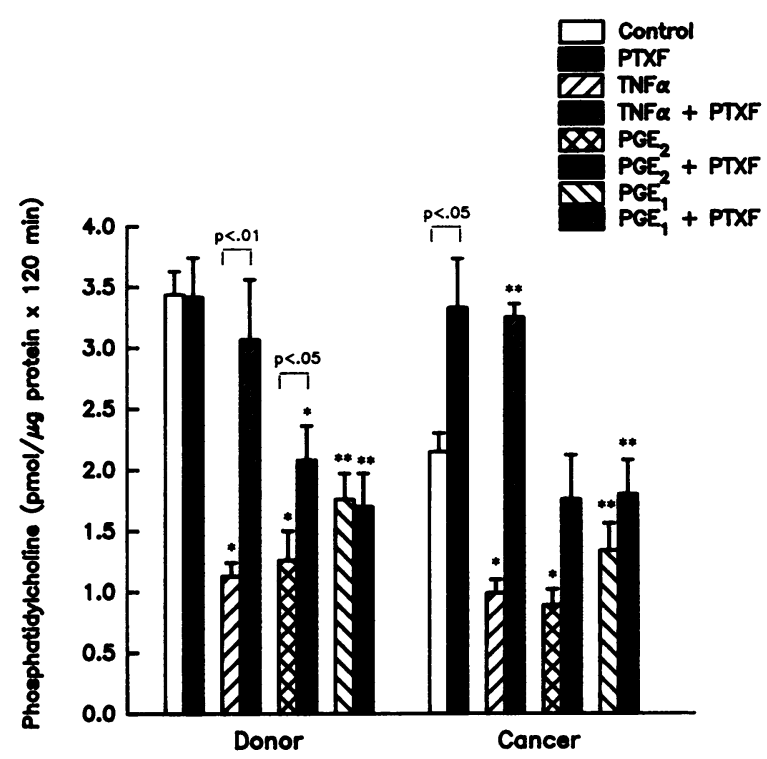

Figure 4. Effect of PTXF ( $100 \mu \mathrm{g} / \mathrm{ml})$ alone, and of TNF $\alpha$ ( $100 \mathrm{ng}$ / $\mathrm{ml}), \mathrm{PGE}_{2}\left(10^{-7} \mathrm{~mol} / \mathrm{liter}\right)$, and $\mathrm{PGE}_{1}\left(10^{-7} \mathrm{~mol} / \mathrm{liter}\right)$, with or without PTXF, on the synthesis of PC by type II pneumocytes isolated from normal (Donor, $n=14$ ) and cancer-bearing lungs (Cancer, $n=11$ ). $* P<0.01$ and $* * P$ vs control.

great quantities of TNF $\alpha$ after being activated (18). On the other hand, there is recent evidence that the production and effects of TNF $\alpha$ are generally confined to organic compartments (19). Therefore, in cancer patients the metabolic consequences of TNF $\alpha$ could be more apparent within the tumor-bearing organ than elsewhere.

Beneficial effects of PTXF have been reported in experimental models of septic shock and ARDS (11). This substance decreased the production of TNF $\alpha$ by activated macrophages (20) and has proven capable of blocking some effects of TNF $\alpha$ on the endothelium (21). Our results show clearly that PTXF can also block the inhibitory effect of TNF $\alpha$ on the synthesis of PC. The greatest effect of PTXF was observed when pneumocytes from cancer patients were used. In this condition, PTXF was not only capable of blocking the effect of TNF $\alpha$, but it also increased the production of $\mathrm{PC}$ in the absence of the cytokine, since the final PC levels were similar to those found in pneumocytes from donors in the absence of TNF $\alpha$. This suggests that the mechanism of functional impairment induced by cancer and by TNF $\alpha$ could be common to both situations, therefore supporting the hypothesis that some of the alterations observed in lung cancer could be due to chronic paracrine exposure to TNF $\alpha(1,22)$. The above finding also makes unlikely the possibility that the reduction in basal PC synthesis observed in the cancer group pneumocytes could be due to cell damage secondary to the different harvesting procedure or any other variable.

Considerable efforts have been devoted to clarify the postreceptor mechanism of TNF $\alpha$. However, the available data are difficult to interpret, since they have been obtained on a variety of cells types and animal species that respond differently to TNF $\alpha$. Our results show that prostaglandins have a role in mediating the TNF $\alpha$ inhibitory effect. This finding is in line with previous reports which suggest that the release of arachidonic acid from phospholipids is a critical element in the signaling pathway used by TNF $\alpha$ and is essential to the rapid cytotoxic 

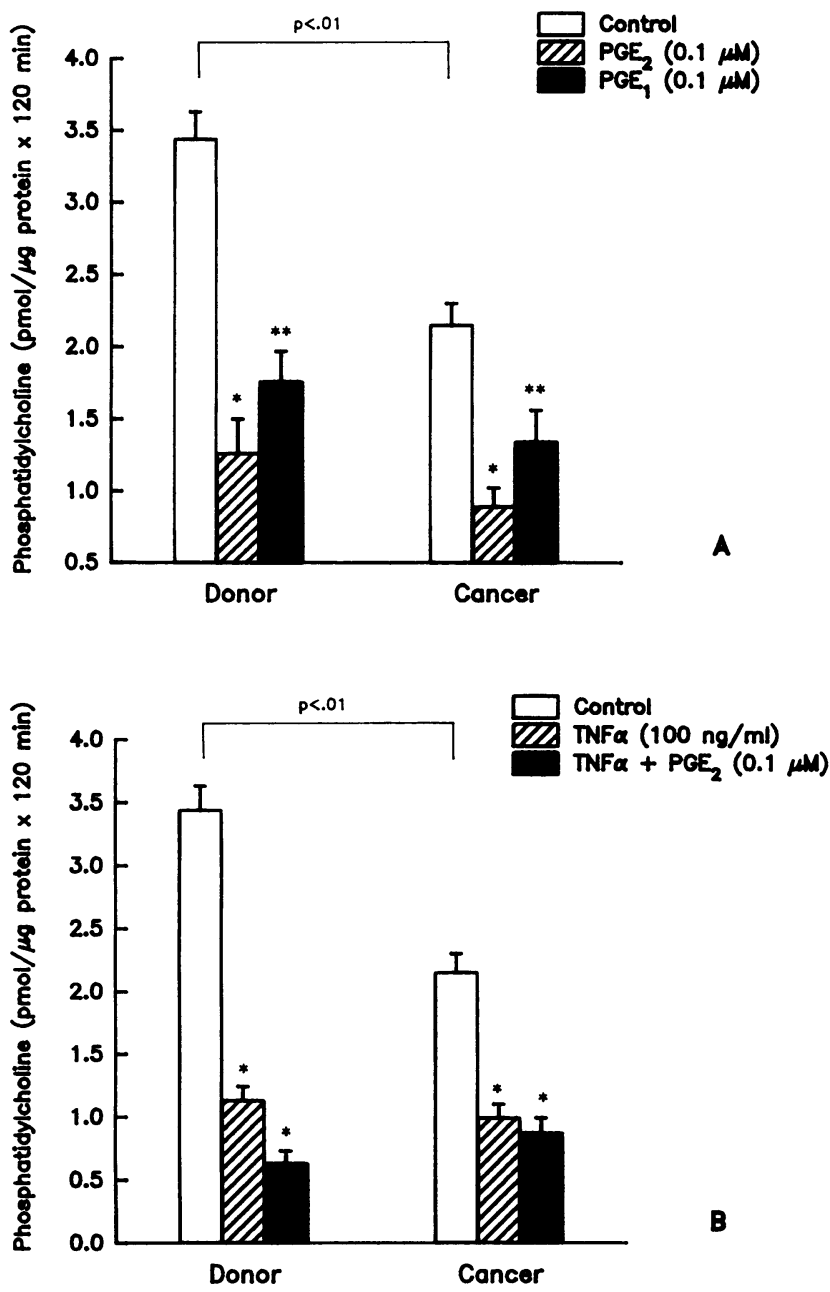

Figure 5. Effect of $\mathrm{PGE}_{2}, \mathrm{PGE}_{1}(A)$, or TNF $\alpha+\mathrm{PGE}_{2}(B)$ on $\mathrm{D}-[\mathrm{U}-$ ${ }^{14} \mathrm{C}$ ] glucose incorporation into $\mathrm{PC}$ by type II pneumocytes isolated from normal (Donor, $n=14$ ) and cancer-bearing lungs (Cancer, $n=11$ ). ${ }^{*} P<0.01$ and $* * P<0.05$ vs control.

response elicited by TNF $\alpha$ (7). In fact, TNF $\alpha$ has been shown to induce expression of prostaglandin endoperoxide synthase, a key enzyme in the formation of prostaglandins, in both neutrophils and endothelial cells (23).

Cyclooxygenase inhibitors improve physiologic parameters and survival after endotoxin (9) or TNF $\alpha$ (8) challenge. However, it is clear that not all of the physiologic changes of endotoxemia seen in vivo are due to cyclooxygenase products. Similarly, it is apparent that not all the effects of TNF $\alpha$ are mediated by arachidonate metabolites (9). In concordance with this concept, our data suggest that the mechanism by which TNF $\alpha$ inhibits PC synthesis is only partially mediated by prostaglandins. In fact, the TNF $\alpha$ effect on donor type II pneumocytes seems to have at least two components, one of them being prostaglandin-mediated and suitable to indomethacin blocking. In this latter component, metabolites from both the cyclo- and the lipoxygenase pathways are implicated. In type II pneumocytes from the cancer group, however, the TNF $\alpha$ effect appears to be mediated exclusively by arachidonic acid metabolites. It is known that TNF $\alpha$ affects fat metabolism in a much greater way in healthy humans than in patients with disseminated neo-
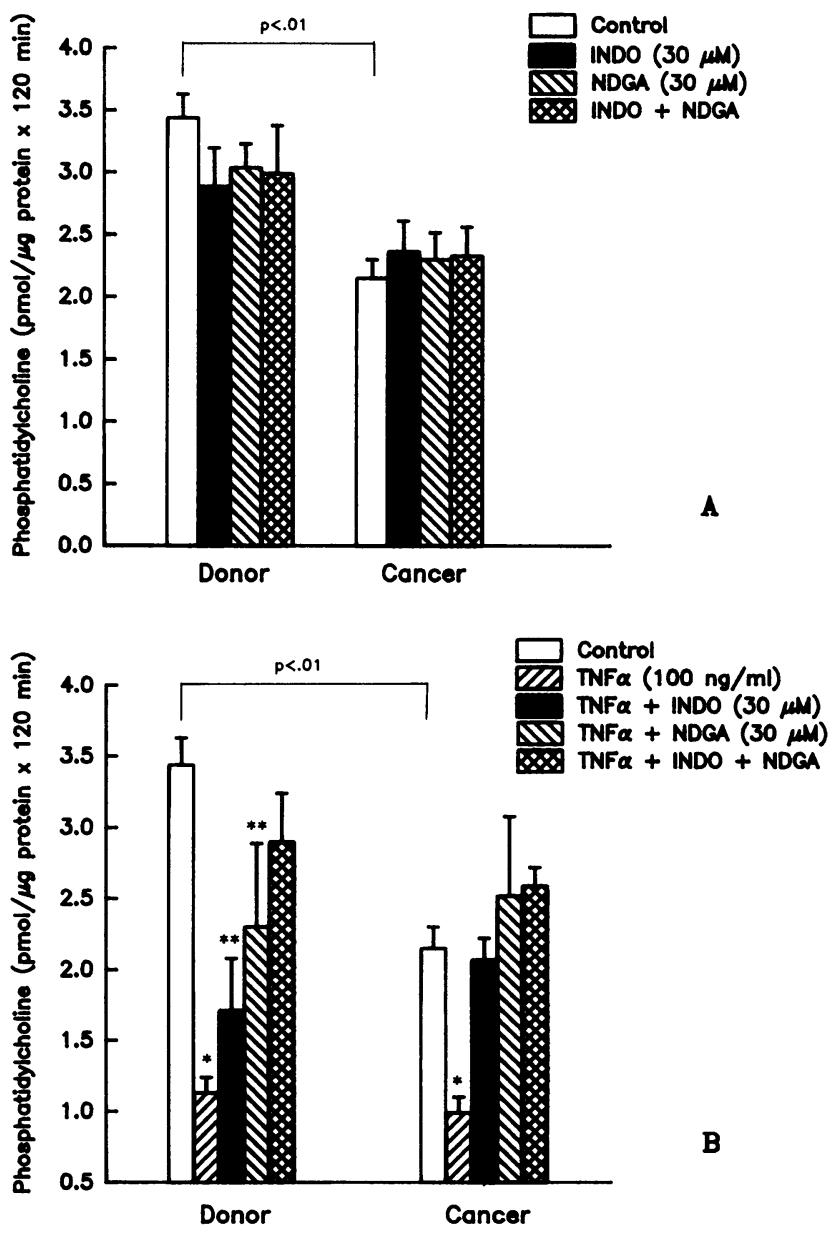

Figure 6. Effect of indomethacin (INDO), NDGA, or both $(A)$ on the synthesis of PC by type II pneumocytes isolated from normal (Donor, $n=14$ ) and cancer-bearing lungs (Cancer, $n=11$ ). Influence of these substances on the inhibitory effect displayed by TNF $\alpha(B) .{ }^{*} P<0.01$ vs all others; $* * P<0.01$ vs control.

plasia. It is believed that this behavior is because of a partial tolerance (1) to TNF $\alpha$ in cancer patients, secondary to their prolonged exposure to this cytokine (22). In the face of these observations, it could be hypothesized that cells from the cancer group have acquired tolerance to the prostaglandin-independent TNF $\alpha$ effects.

Several lines of evidence suggest the importance of phospholipases in the mechanism by which TNF $\alpha$ exerts its actions. In addition to their well known arachidonate-releasing action, these enzymes can contribute to the TNF $\alpha$ effect on pneumocytes by other mechanisms. In the last few years, it has been observed that an increase in the turnover of PC is an early event in the action of diverse agonists. Diverse cell types can synthesize and secrete group II phospholipase (PL) $\mathrm{A}_{2}$ upon stimulation in vitro with cytokines (24), and several distinct forms of $\mathrm{PLA}_{2}$ are present in the lung (25). Incubation of type II cells with $\mathrm{PLA}_{2}$ inhibitor or $\mathrm{PLA}_{2}$ activator resulted in increased or decreased synthesis of PC (25), respectively. Therefore, $\mathrm{PLA}_{2}$ activity may have an important physiologic role in modulating degradation and synthesis of surfactant by the lung epithelium, and it has a further important role in the remodeling of monoenoic PC to form the disaturated species. 
Also in ARDS, PLA A $_{2}$ seems to actively degrade surfactant PC (3), with the corresponding accumulation of its degradation product LPC. Nevertheless, this mechanism seems not to be present in vitro because we did not find any increase in LPC labeling in the presence of TNF $\alpha$ (data not shown). A possible explanation is that other cellular types (24) may be the primary source of the in vivo detected PLA 2 activity.

Previous reports indicate that cleavage of phosphoinositides by PLC leads to the production of two second messengers: diacylglycerol and inositol phosphates (26), which could also be mediators of the TNF $\alpha$ effect. On the other hand, it has been found (27) that partially reduced oxygen species decrease surfactant synthesis by type II cells, suggesting that type II cell damage could be related to $\mathrm{H}_{2} \mathrm{O}_{2}$ production. We did not investigate the effect of TNF $\alpha$ on $\mathrm{H}_{2} \mathrm{O}_{2}$ production, but this hypothesis is consistent with several observations (28) showing that reactive oxygen species are involved in the mediation of some effects of TNF $\alpha$. Both hypotheses could be related in that an enhancement in phosphoinositide turnover rate could increase the concentration of arachidonic acid and prostaglandins (26), which have been otherwise implicated extensively in the production of free radicals. Indomethacin and NDGA are not known to be oxygen radical scavengers in the doses used in this study. Generation of these other toxic mediators may explain in part why indomethacin or NDGA did not entirely prevent the TNF $\alpha$ effect.

PTXF increases intracellular levels of cAMP by inhibiting phosphodiesterase activity. This increase in cAMP seems to play a role in decreasing lung injury (11). Additionally, it has been shown that PTXF is a potent inhibitor of the formation of free radicals (29). Our finding that PTXF was not able to completely revert the prostaglandin effect, in contrast with that of TNF $\alpha$, may have an explanation in the reported effect of PTXF as an inhibitor of both PLA 2 and PLC (30). Therefore, the blocking action of PTXF on the prostaglandin-mediated component of the TNF $\alpha$ effect would be mainly at the level of arachidonic acid release from the membrane phospholipids.

In summary, we have shown that TNF $\alpha$ caused a significant reduction in surfactant synthesis by isolated type II human pneumocytes and that type II pneumocytes from lung cancer patients, although they continue to respond to TNF $\alpha$, produced less surfactant PC in vitro than did those of previously healthy cadaveric organ donors. These results suggest that TNF $\alpha$ may contribute to the pathophysiology of ARDS by inhibiting the synthesis of surfactant PC and also support the hypothesis of in vivo production of TNF $\alpha$ in lung cancer patients, with consequent chronic exposure of the epithelial cells of the lung to this cytokine by a paracrine or systemic pathway. The observation that the TNF $\alpha$ effect was not prevented completely by the blockage of the arachidonic acid metabolism suggests that other mediators should also be implicated.

Additionally, we have found that the inhibitory effect of TNF $\alpha$ can be totally blocked by PTXF and that PTXF is even able to reverse the basal secretory inhibition of the cancer patients' pneumocytes and bring it to levels similar to those of the donor group. The ability of PTXF to antagonize the acute effects of TNF $\alpha$ on type II pneumocytes, and apparently also the chronic effects of this cytokine, suggests that it may have a therapeutic role in ARDS and sepsis.

\section{Acknowledgments}

The writers thank the nurses of the transplant team of the Hospital Universitario San Carlos and especially R. del Barrio, transplant coordinator of this center, for their constant and altruistic collaboration.

This report was partially financed by Fondo Investigaciones Sanitarias $(93 / 0150)$.

\section{References}

1. Tracey, K. J., H. Wei, K. R. Manogue, Y. Fong, D. G. Hesse, H. T. Nguyen, G. C. Kuo, B. Beutler, R. S. Cotran, A. Cerami, and S. F. Lowry. 1988. Cachectin/ tumor necrosis factor induces cachexia, anemia, and inflammation. J. Exp. Med. 167:1211-1227.

2. Tracey, K. J., S. F. Lowry, and A. Cerami. 1988. Cachectin/TNF $\alpha$ in septic shock and septic adult respiratory distress syndrome. Am. Rev. Respir. Dis. 138:1377-1379.

3. Hallman, M., R. Spragg, J. H. Harrel, K. M. Moser, and L. Gluck. 1982. Evidence of lung surfactant abnormality in respiratory failure. Study of bronchoalveolar lavage phospholipids, surface activity, phospholipase activity and plasma myoinositol. J. Clin. Invest. 70:673-683.

4. Gregory, T. J., W. J. Longmore, M. A. Moxley, J. A. Whitsett, C. R. Reed, A. A. Fowler III, L. D. Hudson, R. J. Maunder, C. Crim, and T. M. Hyers. 1991. Surfactant chemical composition and biophysical activity in acute respiratory distress syndrome. J. Clin. Invest. 88:1976-1981.

5. Nash, J. R., P. J. McLaughlin, C. Hoyle, and D. Roberts. 1991. Immunolocalization of tumour necrosis factor alpha in lung tissue from patients dying with adult respiratory distress syndrome. Histopathology (Oxf.). 19:395-402.

6. Dayer, J.-M., B. Beutler, and A. Cerami. 1985. Cachectin/tumor necrosis factor stimulates collagenase and prostaglandin $E_{2}$ production by human synovial cells and dermal fibroblasts. J. Exp. Med. 162:2163-2168.

7. Reid, T., C. S. Ramesha, and G. M. Ringold. 1991. Resistance to killing by tumor necrosis factor in an adipocyte cell line caused by a defect in arachidonic acid biosynthesis. J. Biol. Chem. 266:16580-16586.

8. Wheeler, A. P., W. D. Hardie, and G. R. Bernard. 1992. The role of cyclooxygenase products in lung injury induced by tumor necrosis factor in sheep. Am. Rev. Respir. Dis. 145:632-639.

9. Begley, C., M. Ogletree, B. Meyrick, and K. Brigham. 1984. Modification of pulmonary responses to endotoxemia in awake sheep by steroidal and non steroidal anti-inflammatory agents. Am. Rev. Respir. Dis. 130:11401144.

10. Kruse-Elliott, K. T., and N. C. Olson. 1993. CGS 8515 and indomethacin attenuate cytokine-induced cardiopulmonary dysfunction in pigs. Am. J. Physiol. 264:H1076-H1086.

11. Hoffmann, H., J. R. Hatherill, J. Crowley, H. Harada, M. Yonemaru, H. Zheng, A. Ishizaka, and T. A. Raffin. 1991. Early post-treatment with pentoxifylline or dibutiril cAMP attenuates Escherichia coli-induced acute lung injury in guinea pigs. Am. Rev. Respir. Dis. 143:289-293.

12. Skillrud, D. M., and W. J. Martin. 1984. The isolation of rat alveolar type II cells: a simplified approach using Percoll density centrifugation. Lung. 162:245-252.

13. Mason, R. J., S. R. Walker, B. A. Shields, J. E. Henson, and M. S. Williams. 1985. Identification of rat alveolar type II cells with a tannic acid and polychrome stain. Am. Rev. Respir. Dis. 131:786-788.

14. Vara, E., and J. Tamarit-Rodríguez. 1989. Norepinephrine inhibits islet lipid metabolism, ${ }^{45} \mathrm{Ca}^{2+}$-uptake and insulin secretion. Am. J. Physiol. 257:E923E927.

15. Pison, U., W. Seeger, R. Buchhorn, T. Joka, M. Brand, U. Obertacke, H. Neuhof, and K. P. Schmit-Neuerburg. 1989. Surfactant abnormalities in patients with respiratory failure after multiple trauma. Am. Rev. Respir. Dis. 140:10331039.

16. Kips, J. C., J. Tavernier, and R. A. Pauwels. 1992. Tumor necrosis factor causes bronchial hyperresponsiveness in rats. Am. Rev. Respir. Dis. 145:332336.

17. Betsholtz, C., J. Bergh, M. Bywater, M. Pettersson, A. Johnsson, C. H. Heldin, R. Ohlsson, T. J. Knorr, J. Scott, G. I. Bell, and B. Westermark. 1989. Expression of multiple growth factors in a human lung cancer cell line. Int. $J$. Cancer. 39:502-506.

18. Okubo, A., S. Sone, S. M. Singh, and T. Ogura. 1990. Production of tumor necrosis factor- $\alpha$ by alveolar macrophages of lung cancer patients. Jpn. J. Cancer Res. 81:403-409.

19. Tracey, K. J., S. Morgello, B. Koplin, T. J. Fahey III, J. Fox, A. Aledo, K. R. Manogue, and A. Cerami. 1990. Metabolic effects of cachectin/tumor necrosis factor are modified by site of production. Cachectin/tumor necrosis factor-secreting tumor in skeletal muscle induces chronic cachexia, while implantation in brain induces predominantly acute anorexia. J. Clin. Invest. 86:2014-2024.

20. Endres, S., H. J. Fülle, B. Sinha, D. Stoll, C. A. Dinarello, R. Gerzer, and P. C. Weber. 1991. Cyclic nucleotides differentially regulate the synthesis of tumour necrosis factor- $\alpha$ and interleukin $1 \beta$ by human mononuclear cells. Immunology. 72:56-60. 
21. Zheng, H., J. J. Crowley, J. C. Chan, H. Hoffmann, J. R. Hatherill, A Ishizaka, and T. A. Raffin. 1990. Attenuation of tumor necrosis factor-induced endothelial cell cytotoxicity and neutrophil chemiluminescence. Am. Rev. Respir. Dis. 142:1073-1078.

22. Balkwill, F., F. Burke, D. Talbot, J. Tavernier, R. Osborne, S. Naylor H. Durbin, and W. Fiers. 1987. Evidence for tumour necrosis factor/cachectin production in cancer. Lancet. ii:1229-1232.

23. Jones, D. A., D. P. Carlton, T. M. McIntyre, G. A. Zimmerman, and S. M. Prescott. 1993. Molecular cloning of human prostaglandin endoperoxide synthase type II and demonstration of expression in response to cytokines. $J$. Biol. Chem. 268:9049-9054.

24. Hayakawa, M., N. Ishida, K. Takeuchi, S. Shibamoto, T. Hori, N. Oku, F. Ito, and $M$. Tsujimoto. 1993. Arachidonic acid-selective phospholipase $A_{2}$ is crucial in the cytotoxic action of tumor necrosis factor. J. Biol. Chem. 268:11290-11295.

25. Fisher, A. B., Ch. Dodia, A. Chander, and M. Jain. 1992. A competitive inhibitor of phospholipase $A_{2}$ decreases surfactant phosphatidylcholine degradation by the rat lung. Biochem. J. 288:407-411.

26. Rapuano, B. E., and R. S. Bockman. 1991. Tumor necrosis factor-a stimulates phosphatidyl inositol by phospholipase $\mathrm{C}$ to coordinately increase the levels of diacylglycerol, free arachidonic acid and prostaglandins in an osteoblast (MC3T3-E1) cell line. Biochem. Biophys. Acta. 1091:374-384.

27. Baker, R. R., P. C. Panus, B. A. Holm, P. C. Engstrom, B. A. Freeman, and S. Matalon. 1990. Endogenous xanthine oxidase-derived $\mathrm{O}_{2}$ metabolites inhibit surfactant metabolism. Am. J. Physiol. 259:L328-L334.

28. Mathews, L., M. L. Neale, S. K. Jackson, and J. M. Stark. 1987. Tumour cell killing by tumour necrosis factor: inhibition by anaerobic conditions, free radical scavengers and inhibitors of arachidonate metabolism. Immunology. 62:153-155.

29. Ciufetti, G., M. Mercury, R. Lombardini, R. Paltricia, G. Lupatelli, L. Santanbroggio, and E. Mannarino. 1991. Use of pentoxifylline as an inhibitor of free radical generation in peripheral vascular disease. Eur. J. Clin. Pharmacol. 41:511-515.

30. Rossignol, L., M. Plantavid, H. Chap, and L. Douste-Blazy. 1988. Effects of two methylxanthines, pentoxifylline and propentofylline, on arachidonic acid metabolism in platelets stimulated by thrombin. Biochem. Pharmacol. 37:3229 3236 . 